\title{
Genistein attenuated gastric inflammation and apoptosis in Helicobacter pylori-induced gastropathy in rats
}

\author{
Prasong Siriviriyakul ${ }^{1}$, Duangporn Werawatganon ${ }^{1 *} \mathbb{0}$, Nisarat Phetnoo ${ }^{1}$, Kanjana Somanawat ${ }^{1}$, \\ Tanittha Chatsuwann ${ }^{2}$, Naruemon Klaikeaw ${ }^{3}$ and Maneerat Chayanupatkul ${ }^{1}$
}

\begin{abstract}
Background: Helicobacter pylori (H. pylori) infection is a major cause of chronic gastritis, peptic ulcer diseases and cancer. Genistein (4',5,7-trihydroxyisoflavone), a tyrosine-specific-protein kinase inhibitor, has been shown to exert an anti-inflammatory property. The aim of this study was to examine the treatment effects of genistein and its mechanisms in rats with H. pylori infection.

Methods: Eighteen male Sprague-Dawley rats were divided into three groups ( 6 rats per group): (1) control group (Con); (2) H. pylori infected group (HP): the rats were inoculated with H. pylori $\left(10^{8-} 10^{10} \mathrm{CFU} / \mathrm{mL} ; 1 \mathrm{~mL} /\right.$ rat.) for 3 consecutive days; and (3) HP + genistein group ( $\mathrm{HP}+\mathrm{Gen}$ ): the rats were inoculated with H. pylori as above. Then, they were gavaged with genistein ( $16 \mathrm{mg} / \mathrm{kg} \mathrm{BW}$ ) for 14 days. Gastric tissue was used for the determination of nuclear factor (NF)-KB expression by immunohistochemistry (IHC), degree of apoptosis by the terminal deoxynucleotidyl transferasemediated dUTP nick-end labeling (TUNEL) reaction, and histopathology. Serum samples were used to measure the levels of tumor necrosis factor-alpha (TNF-a) and cytokine-induced neutrophil chemoattractant-1 (CINC-1).

Results: Rats in the HP group had significantly higher levels of pro-inflammatory mediators, NF-KB expression and apoptotic cells when compared with the Con group, and these markers significantly decreased in HP + Gen group when compared with the HP group. The histopathology of HP group showed moderate gastric inflammation and many HP colonization. Gastric pathology in HP + Gen group demonstrated the attenuation of inflammatory cell infiltration and H. pylori colonization.
\end{abstract}

Conclusion: Genistein exerted its gastroprotective effects through the reduction of pro-inflammatory mediators, nuclear receptor NF-KB expression and gastric mucosal apoptosis in rats with H. pylori-induced gastropathy.

Keywords: Genistein, H. pylori, Apoptosis, Gastric inflammation, Gastropathy

\section{Background}

Helicobacter pylori (H. pylori) is a spiral-shaped gramnegative bacterium and a major player in the development of gastroduodenal diseases. The prevalence of $H$.

\footnotetext{
*Correspondence: dr.duangporn@gmail.com

1 Department of Physiology, Faculty of Medicine, Alternative and Complementary Medicine for Gastrointestinal and Liver Diseases Research Unit, Chulalongkorn University, Bangkok 10330, Thailand Full list of author information is available at the end of the article
}

pylori infection ranges from 15 to $90 \%$ depending on the regions and the ethnicities [1]. Several studies demonstrated the association between $H$. pylori infection and numerous gastrointestinal diseases, such as chronic gastritis, peptic ulcer disease, gastric mucosa-associated lymphoid tissue (MALT) lymphoma, and gastric cancer [2-4]. To date, H. pylori infection remains the cause of major public health problem, especially in developing countries. 
H. pylori causes gastric problems by first adhering to and colonizing the gastric mucosa. The bacteria then inject its virulent factors, particularly cagA protein, into the host epithelial cells using the type IV secretory system $[3,5]$. These virulent factors affect host epithelial cell cytoskeletal rearrangements and activate NF-kB pathway, which subsequently induce IL-8 expression and release [6-8]. IL-8 is a potent chemotactic factor, thus attracting neutrophils and lymphocytes to the affected area. Consequently, these inflammatory cells release pro-inflammatory cytokines, such as tumor necrosis factor-alpha (TNF- $\alpha$ ) and IL- 6 leading to gastric mucosal injury and gastric epithelial cell apoptosis [9-11]. In response to TNF- $\alpha$ stimulation, gastric epithelial cells also release cytokine-induced neutrophil chemoattractant-1 (CINC-1) which works in concert with IL-8 in the attraction of neutrophils adding further insults to the injured mucosa [12].

The standard of care for the treatment of $H$. pylori infection includes the combination of acid suppression medication (proton pump inhibitor or vonoprazan) and 1-3 antibiotics for 7-14 days with the eradication rate ranging from 60 to $90 \%$ [13]. However, the resistance rates of the commonly used antibiotics can be more than $15 \%$ in some regions leading to unacceptable cure rates [14]. Furthermore, antibiotic use is associated with side effects which affects patient compliance, and may alter gut microbiota [15]. In light of these drawbacks, we strive to find an alternative and a more natural treatment for $H$. pylori-induced gastritis.

Genistein $\left(4^{\prime}, 5,7\right.$-trihydroxyisoflavone $)$ is a natural isoflavone found in soybeans and soy products. In vitro studies suggest that genistein is a specific inhibitor of tyrosine kinases [16], reduces inflammation through the inhibition of NF-kB activation and TNF- $\alpha$ production [17-19], and possesses anti-microbial properties to certain bacteria [20]. With these properties, we hypothesize that genistein may have a role in the treatment of $H$. pylori infection. Its treatment effect has also been implied by a case-control study by Ko KP and colleagues, which showed that genistein consumption was associated with the reduction in gastric cancer, particularly in $H$. pylori-infected subjects [21]. To the best of our knowledge, the effects of genistein on $H$. pyloriinduced gastropathy in an experimental animal model have never been investigated. In the present study, we aimed to evaluate the anti-inflammatory effects of genistein, which may attenuate gastropathy through the suppression of nuclear receptor NF- $\mathrm{KB}$ expression, pro-inflammatory mediator production (i.e. TNF- $\alpha$ and CINC-1), and gastric epithelial cell apoptosis in rats with $H$. pylori infection.

\section{Methods}

\section{Animal and chemical preparations}

Eighteen male Sprague-Dawley rats (National Laboratory Animal Center, Mahidol University, Nakorn Pathom, Thailand) were used. The weight of rats ranged from 180 to $200 \mathrm{~g}$ at the start of the experiment. All experiments and procedures carried out on the animals have been approved by the Ethics Committee of the Faculty of Medicine, Chulalongkorn University, Bangkok, Thailand (IRB No. 8/57). Rats were housed in a controlled temperature room at $25 \pm 1{ }^{\circ} \mathrm{C}$ and a $12 \mathrm{~h}$ light/dark cycle. All animals were allowed to acclimate to the new environment for 1 week prior to initiation of the experiment. Genistein (Batch number 0439241-61) were purchased from Cayman chemical company and dissolved in 0.1\% DMSO.

\section{H. pylori strains and growth condition}

H. pylori strains for all experiments were obtained from peptic ulcer patients at King Chulalongkorn Memorial Hospital. The bacteria were grown in brucella broth (pH7.0) supplemented with $10 \%$ goat serum for $24 \mathrm{~h}$ at $37^{\circ} \mathrm{C}$ in an automatic $\mathrm{CO}_{2}-\mathrm{O}_{2}$ incubator under microaerophillic conditions $\left(85 \% \mathrm{~N}_{2}, 10 \% \mathrm{CO}_{2}\right.$ and $\left.5 \% \mathrm{O}_{2}\right)$.

\section{H. pylori inoculation model}

The rats were inoculated with $H$. pylori using the method of Werawatganon et al. 2014 [22]. A 3-day treatment of streptomycin suspended in drinking water $(5 \mathrm{mg} / \mathrm{mL})$ was given to all rats in $H$. pylori groups prior to $H$. pylori inoculation. Then, they were inoculated with $H$. pylori suspension $\left(10^{8-10} \mathrm{CFU} / \mathrm{mL} ; 1 \mathrm{~mL} / \mathrm{rat}\right)$ by intragastric tube twice a day, $4 \mathrm{~h}$ apart for 3 consecutive days. Two weeks later the rats were sacrificed.

Eighteen rats were randomly divided into three groups (six rats per group) as follows: [1] control group (Con), rats were treated with $0.1 \%$ DMSO $(1 \mathrm{~mL} / \mathrm{rat})$ for 17 days [2]; H. pylori-infected group (HP), after $H$. pylori inoculation, rats were gavaged with $0.1 \%$ DMSO $(1 \mathrm{~mL} / \mathrm{rat})$ as a vehicle control for 14days; and, [3] HP + genistein group $(\mathrm{HP}+\mathrm{Gen})$, after $H$. pylori inoculation, rats were gavaged with genistein $(16 \mathrm{mg} / \mathrm{kg} \mathrm{BW})$ dissolved in $0.1 \%$ DMSO for 14 days. At the end of the experiment, the rats were euthanized with overdose sodium pentobarbital (dose $>50 \mathrm{mg} / \mathrm{kg}$ ) before collecting gastric tissue and blood samples.

\section{Measurement of TNF- $a$ and CINC-1 levels in serum}

Blood samples were obtained by cardiac puncture and centrifuged at $1500 \times \mathrm{g}$ for $10 \mathrm{~min}$. The supernatant was stored at $-80^{\circ} \mathrm{C}$ until measurement. The serum concentrations of TNF- $\alpha$ and CINC- 1 were measured by a rat TNF- $\alpha$ enzyme-linked immunosorbent assay and a rat 
CXCL1/CINC-1 Immunoassay ( $\mathrm{R}$ and D systems, USA), respectively, according to the manufacturer's protocols.

\section{NF-kB expression by immunohistochemistry (IHC) assay}

Tissue sections were deparaffinized with xylene and ethanol for $10 \mathrm{~min}$. The antigen was then retrieved with citrate buffer $\mathrm{pH} 6.0$ in microwave for $13 \mathrm{~min}$. Slides were incubated with 3\% hydrogen peroxide (Merck, Hohenbrunn, Germany) for $5 \mathrm{~min}$ and with 3\% normal horse serum (Gibco, Carlsbad, CA, USA) for 20 min to block endogenous peroxidase activity and nonspecific binding, respectively. Subsequently, gastric sections were incubated in a humidified chamber at room temperature for $1 \mathrm{~h}$ with a polyclonal antibody against NF-k $\beta$ (sc109; Santa Cruz Biotechnology, Santa Cruz, CA, USA) at a dilution of 1:100. Slides were then incubated with biotinylated anti-rabbit immunoglobulin (DAKO, Glostrup, Denmark) for $30 \mathrm{~min}$. When the color development with diaminobenzidine (DAKO, Glostrup, Denmark) was seen, sections were counterstained with hematoxylin. Under light microscopy, positive cells were gastric epithelial cells with dark brown-stained nuclei. Under medium magnification ( $\times 10$ lens), one thousand gastric epithelial cells were manually counted for each rat to quantify the percentage of immune-positive cells. This procedure was performed by a pathologist who was blinded to the experiment. The percentage of immunoreactive cells was calculated as follows. technique before paraffin embedding and sections were cut at $5 \mu \mathrm{m}$ thickness. The sections were stained with hematoxylin-eosin (HE) and Giemsa staining methods. One experienced gastrointestinal pathologist examined all blinded samples by using light microscope following the updated Sydney System. ${ }^{[46]}$ All histopathological findings were recorded and graded by using the gastric inflammation score and bacterial colonization as follows: gastric inflammation score: 0: no infiltration of polymorphonuclear and mononuclear; 1 : mild infiltration of polymorphonuclear and mononuclear; 2: moderate infiltration of polymorphonuclear and mononuclear; 3 : severe infiltration of polymorphonuclear and mononuclear. H. pylori colonization score: 0: no bacteria detected; 1: few colonizations; 2: many colonizations.

\section{Statistical analysis}

All data were presented as mean and standard deviation (SD). For comparison among all groups of animals, one-way analysis of variance (one-way ANOVA) comparisons were employed. Descriptive statistics were used for histological examination of the stomach. Differences were considered statistically significant at $P<0.05$. The data were analyzed using SPSS software version 17.0 for Windows.

Percentage of immunoreactive cells $(\%)=($ number of immunoreactive cells $\times 100) / 1000$.

\section{Gastric epithelial cells apoptosis by terminal deoxynucleotidyl transferase dUTP nick end labeling (TUNEL) assay}

Apoptosis was determined by the presence of apoptotic nuclei in the gastric sections using fragment end labeling of DNA (Apoptosis detection kit, Chemicon, United States). First, the DNA fragments were bound to a peroxidase-conjugated antidigoxigenin antibody. After the development of a dark brown color by applying diaminobenzidine to the section, slides were counterstained with hematoxylin. Positive cells were those with dark brown nuclei under the light microscopy. To measure the degree of apoptosis, a total of 1000 gastric epithelial cells were counted in each rat to determine the numbers of the dark brown-stained cells. The data are presented as a percentage (\%) of apoptotic cells using the following formula: the percentage of apoptotic cells $(\%)=$ (numbers of positive stained cells $\times 100$ )/1000.

\section{Gastric histopathology}

A portion of gastric antral tissue was fixed in 10\% formaldehyde solution. They were processed by a routine

\section{Results \\ Changes in levels of pro-inflammatory mediators, serum TNF- $a$ and CINC-1}

As shown in Fig. 1a and b, the HP group had significantly higher levels of serum TNF- $\alpha$ and CINC-1 when compared with the Con group $(47.92 \pm 13.74 \mathrm{pg} / \mathrm{mL}$ vs. $18.95 \pm 7.94 \mathrm{pg} / \mathrm{mL}$ and $137.28 \pm 47.67 \mathrm{pg} / \mathrm{mL}$ vs. $72.27 \pm 6.07 \mathrm{pg} / \mathrm{mL}$, respectively, $P<0.05)$. As expected, in the $\mathrm{HP}+\mathrm{Gen}$ group, the serum levels of TNF- $\alpha$ and CINC-1 significantly decreased when compared with the HP group $(29.24 \pm 11.80 \mathrm{pg} / \mathrm{mL}$ vs. $47.92 \pm 13.74 \mathrm{pg} /$ $\mathrm{mL}$ and $80.48 \pm 12.37 \mathrm{pg} / \mathrm{mL}$ vs. $137.28 \pm 47.67 \mathrm{pg} / \mathrm{mL}$, respectively, $P<0.05)$.

\section{NF-kB expression in gastric epithelial cells}

The percentage of NF-kB immunoreactive cells significantly increased in the HP group when compared with the Con group $(16.67 \% \pm 0.71 \%$ vs. $10.64 \% \pm 0.50 \%$, respectively, $p<0.05)$. The expression of NF-kB in gastric epithelial cells was attenuated by genistein administration in $\mathrm{HP}+\mathrm{Gen}$ group when compared with the HP group $(11.87 \% \pm 0.42 \%$ vs. $16.67 \% \pm 0.71 \%$, respectively, 


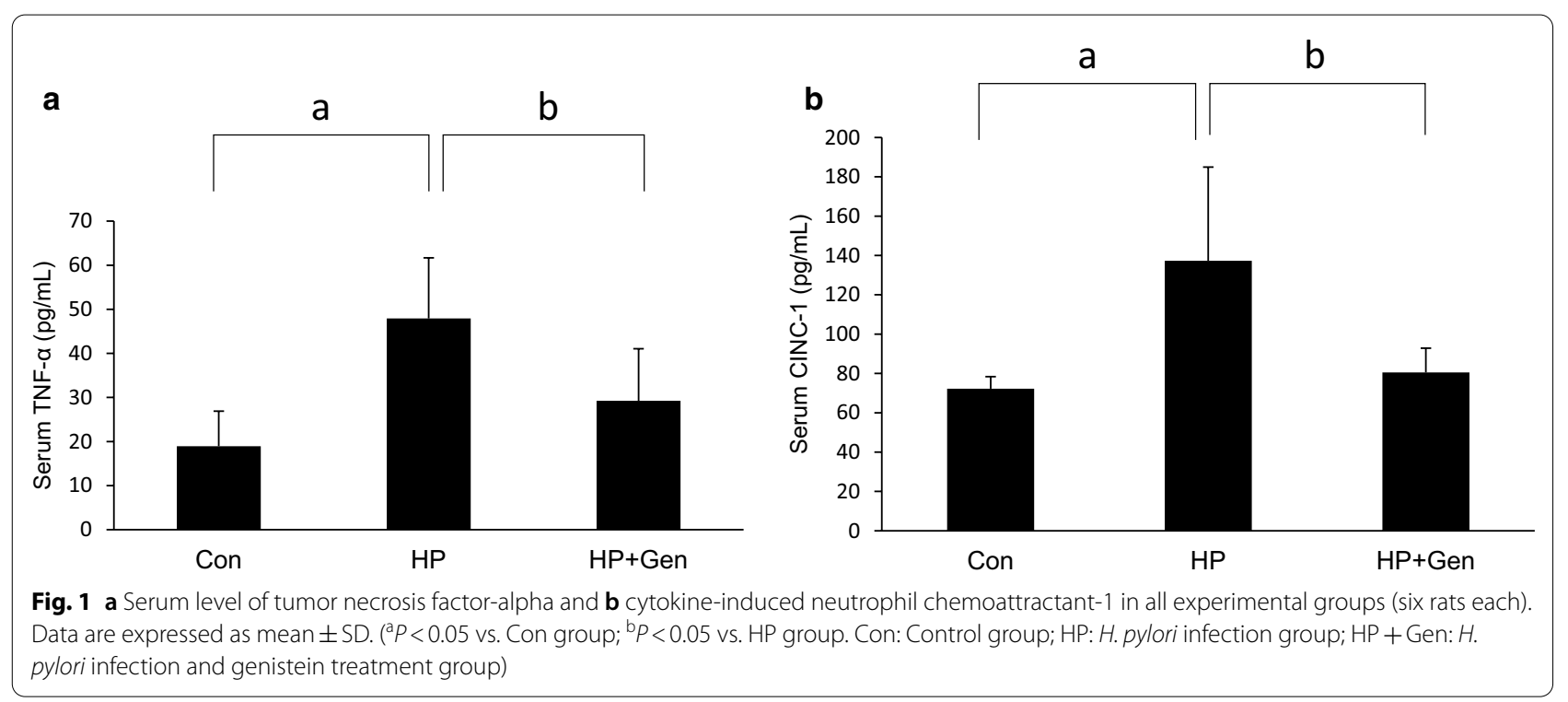

$p<0.05)$. The average percentages of NF- $\mathrm{kB}$ positive gastric epithelial cells in all the groups are shown in Fig. $2 \mathrm{a}$. The representative images of immunohistochemical study of NF-kB expression in each group are shown in Fig. 2c.

\section{Gastric epithelial cell apoptosis}

As illustrated in Fig. 2b, the percentage of apoptotic cells significantly increased in the HP group when compared with the Con group $(7.52 \% \pm 0.74 \%$ vs. $0.70 \% \pm 0.31 \%$, respectively, $p<0.05)$. After treatment with genistein, the percentage of apoptotic cells significantly decreased in $\mathrm{HP}+$ Gen group when compared with the HP group $(5.01 \% \pm 0.67 \%$ vs. $7.52 \% \pm 0.74 \%$, respectively, $p<0.05)$. The representative images of gastric sections processed for apoptosis by the terminal deoxynucleotidyl transferase mediated dUTP nick-end labeling (TUNEL) reaction are shown in Fig. 2d.

\section{Histopathological changes}

As summarized in Table 1, the gastric histopathology was normal in the Con group, whereas in the HP group, the histopathology showed mild $(n=3)$ to moderate $(n=3)$ gastric inflammation. For $H$. pylori colonization, the HP group showed few $(n=3)$ and many $(n=3)$ colonization, while $H$. pylori colonization was not observed in the Con group. In $\mathrm{HP}+\mathrm{Gen}$ group, histopathological changes were attenuated when compared to the HP group, especially in terms of inflammatory cell infiltration. Almost all of the gastric tissues in the $\mathrm{HP}+$ Gen group showed no infiltration of inflammatory cells $(n=5)$. Similarly, $H$. pylori colonization was reduced in the $\mathrm{HP}+\mathrm{Gen}$ group $(n=5)$ (Fig. 3).

\section{Discussion}

H. pylori infection is associated with the infiltration of polymorphonuclear and mononuclear cells in gastric mucosa. These inflammatory cells release several proinflammatory cytokines, reactive oxygen species, and proteolytic enzymes leading to mucosal damage [3]. Previous studies show that through the activation NF-kB, $H$. pylori induce the expression of IL- 8 and TNF- $\alpha[9,23$, $24]$. Another in vitro study also showed that the stimulation of gastric mucosal cell line with TNF- $\alpha$ led to increased oxidative stress and NF-kB activation with subsequent CINC-1 up-regulation [12]. The results from our study were in line with prior observations. We found that $H$. pylori-infected rats had higher serum levels of TNF- $\alpha$ and $\mathrm{CINC}-1$, and increased expression of NF-kB in gastric epithelial cells as compared with the control group.

(See figure on next page.)

Fig. 2 a The percentage of nuclear factor-kappaB immunoreactive cells (\%) and $\mathbf{b}$ apoptotic cells (\%) in all experimental groups (six rats each). Figure 2c were representative images of immunohistochemistry for NF-kappaB ( $\times 40$ magnification). Positive cells were gastric epithelial cells with brown-stained nuclei. Figure $2 \mathbf{d}$ were representative images of TUNEL stain ( $\times 100$ magnification). Arrows indicated gastric epithelial cells with brown-stained nuclei. Data are expressed as mean \pm SD. ( ${ }^{a} P<0.05$ vs. Con group; ${ }^{b} p<0.05$ vs. HP group. Con: Control group; HP: H. pylori infection group; HP + Gen: H. pylori infection and genistein treatment group) 


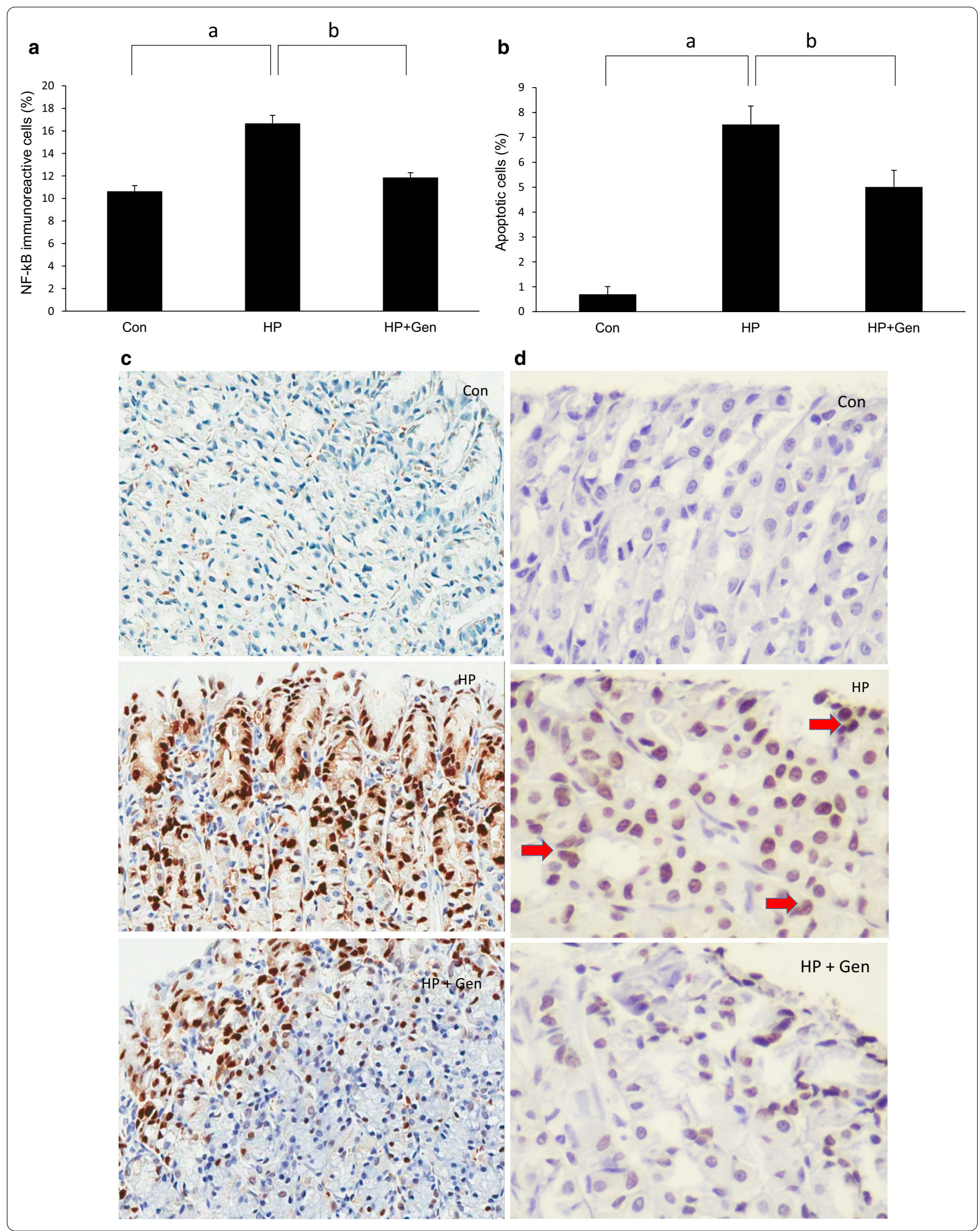


Table 1 Summary of the gastric inflammation and the bacterial colonization score

\begin{tabular}{|c|c|c|c|c|c|c|c|c|}
\hline \multirow[t]{2}{*}{ Group } & \multirow[t]{2}{*}{$\mathrm{N}$} & \multicolumn{4}{|c|}{ Inflammation $^{a}$} & \multicolumn{3}{|c|}{ H. pylori colonization ${ }^{b}$} \\
\hline & & No & Mild & Moderate & Severe & No & Few & Many \\
\hline Con & 6 & 6 & - & - & - & 6 & - & - \\
\hline $\mathrm{HP}$ & 6 & - & 3 & 3 & - & - & 3 & 3 \\
\hline $\mathrm{HP}+\mathrm{Gen}$ & 6 & 5 & 1 & - & - & 5 & 1 & - \\
\hline
\end{tabular}

a Gastric inflammation score: 0: no infiltration of polymorphonuclear and mononuclear; 1: mild infiltration of polymorphonuclear and mononuclear; 2: moderate infiltration of polymorphonuclear and mononuclear; 3 : severe infiltration of polymorphonuclear and mononuclear

${ }^{\mathrm{b}}$ H. pylori colonization score: 0 : no bacteria detected; 1: few colonizations; 2: many colonizations

a

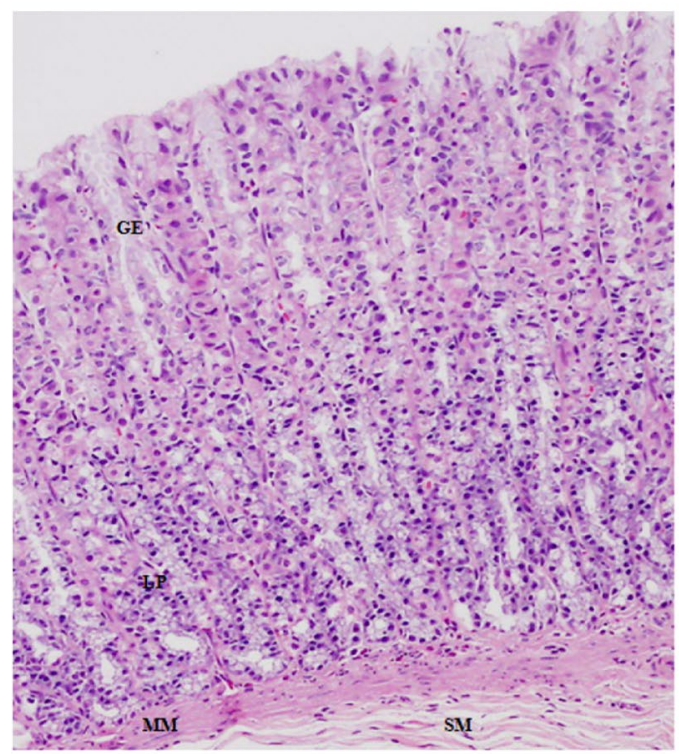

b

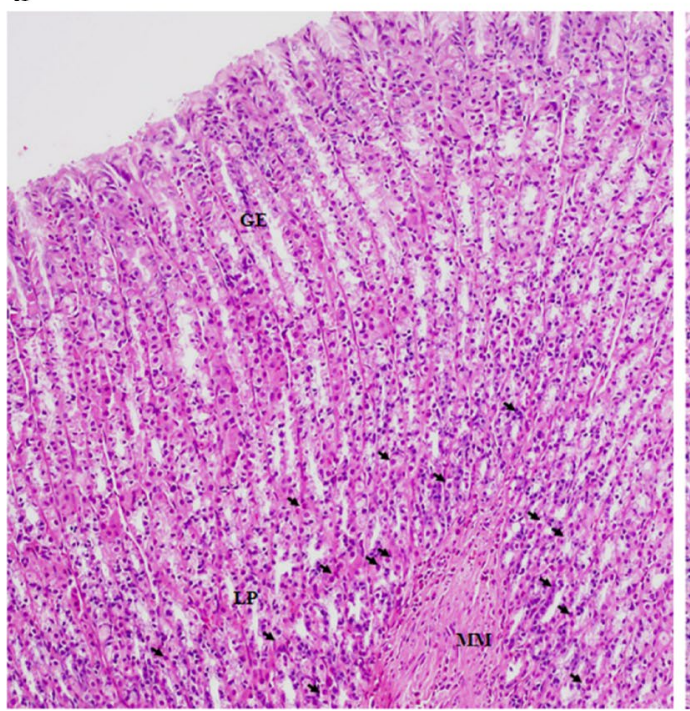

C

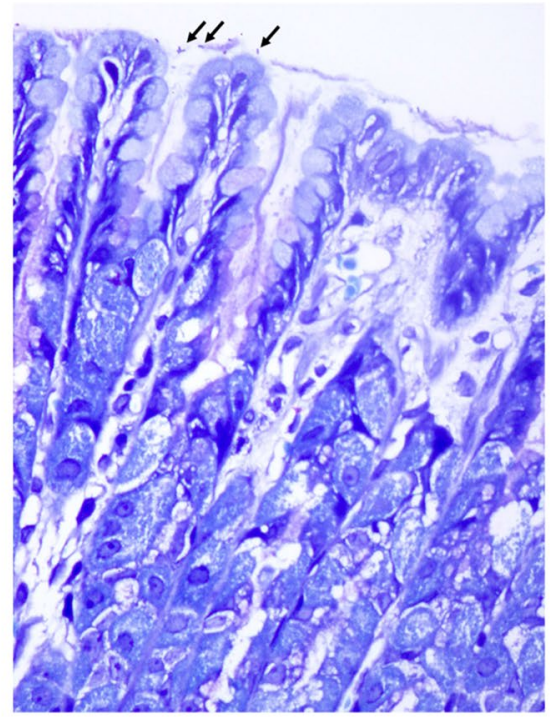

d

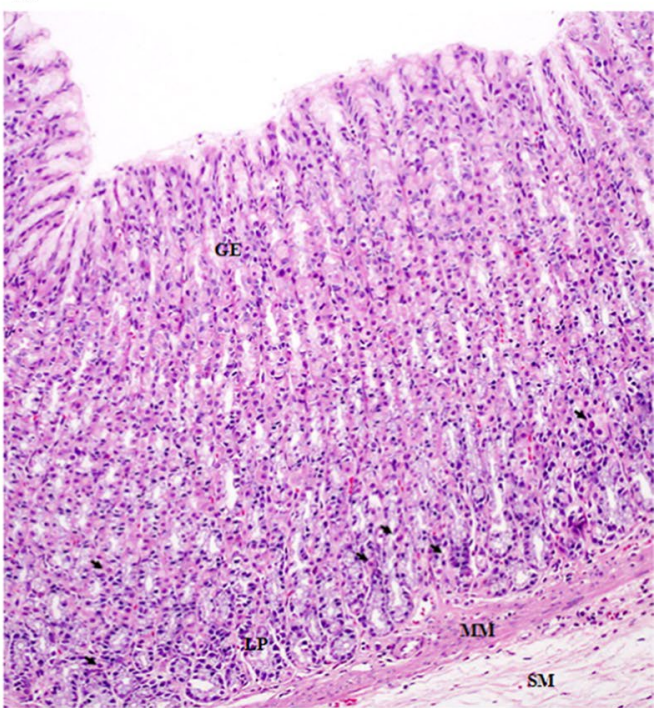

Fig. 3 Gastric histopathology in rats with $H$. pylori infection. a Control group showed normal histopathology $\left(H\right.$ and $\left.E_{1} \times 10\right)$; b $H$. pylori infection group $(H$ and $E, \times 10)$ with arrows indicating inflammatory cell infiltration in the lamina propria; $\mathbf{c} H$. pylori infection group (Giemsa stain, $\times 100)$ with arrows indicating $\mathrm{H}$. pylori; $\mathbf{d} \mathrm{H}$. pylori infection and genistein treatment group $(\mathrm{H}$ and $\mathrm{E}, \times 10)$ with arrows indicating inflammatory cell infiltration in the lamina propria. GE: Gastric epithelium; LP: Lamina propria; MM: Muscularis mucosae; SM: Submucosa 
In vitro and in vivo studies suggest that $H$. pylori induces apoptosis mainly through the intrinsic pathway by means of increased Bak and Bax expression and cytochrome $c$ release from mitochondria [11, 25]. In this study, we noted the increase in gastric epithelial cell apoptosis in H. pylori-infected rats. Similar to our results, Cover TL and colleagues performed an in vitro study using VacA positive $H$. pylori stain and AGS gastric epithelial cells. The authors found that VacA positive $H$. pylori stain could induce a higher level of apoptosis than VacA negative $H$. pylori stain, and purified VacA could dose-dependently induce apoptosis in AGS cells [26]. Similar findings were also seen in a human study by Moss SF and colleagues. They demonstrated a higher degree of gastric epithelial apoptosis in $H$. pylori-infected subjects with subsequent reduction in apoptosis after $H$. pylori eradication [27].

Geinstein, a major isoflavone found in soy-based products and a tyrosine-specific protein kinase inhibitor [16], has been shown to possess anti-neoplastic, antiinflammatory, anti-oxidant, and anti-atherogenic properties [28-30]. Several in vitro studies demonstrated that genistein, as a tyrosine kinase inhibitor, could inhibit $H$. pylori-induced tyrosine-specific protein phosphorylation and IL-8 release from gastric epithelial cells suggesting that genistein could potentially be used in the treatment of $H$. pylori infection [31,32]. In this study, we found that genistein administration reduced serum TNF- $\alpha$ and CINC-1, NF-kB expression, and gastric epithelial apoptosis in $H$. pylori-infected rats. As a result of these changes, gastric histopathology improved in H. pylori-infected rats that received genistein.

An in vitro model of lipopolysaccharide (LPS)-stimulated macrophages elucidated that genistein exerted its inhibitory effect on NK-kB activation through the reduction in lipid peroxidation and the increase in glutathione and anti-oxidant enzyme activities [19]. Additionally, genistein could suppress NK-kB activation in LPS-stimulated macrophages through adenosine monophosphate-activated protein kinase (AMPK) pathway, thereby reducing TNF- $\alpha$ and IL- 6 production [17]. These mechanism likely explained the reduction in NF-kB expression and pro-inflammatory cytokine production after genistein administration in $H$. pylori-infected rats in our study.

In the present study, gastric pathology in the majority of genistein-treated rats showed the disappearance of neutrophil infiltration in conjunction with the decrease in $H$. pylori colonization. Similar findings were reported in a pathology study in humans [33]. The authors showed that neutrophil infiltration diminished in patients with $H$. pylori eradication and the presence of residual neutrophils predicted relapses [33]. Takekawa S and colleagues demonstrated that genistein could reduce the production of thiobarbituric acid reactive substances (TBARS), TNF- $\alpha$ and CINC-1 in gastric mucosa in a rat model of stress-induced mucosal injury [34]. The reduction in CINC-1, a potent neutrophil chemotactic factor, was likely responsible for the disappearance of neutrophil infiltration in a genistein-treated group. Likewise, genistein has been shown to reduce the levels of malondialdehyde and TNF- $\alpha$ in a rat model of indomethacin-induced gastropathy $[35,36]$. The decline in inflammatory responses and oxidative stress also ameliorated gastric mucosal injury and gastric epithelial cell apoptosis in $H$. pylori-infected rats that received genistein.

A prior in vitro study suggested that by binding to $\alpha 5 \beta 1$-integrins on gastric epithelial cell surface, $H$. pylori could induce tyrosine phosphorylation of proteins that were responsible for bacterial adherence to gastric epithelial cells. The adherence of $H$. pylori to gastric cells could be inhibited by tyrosine kinase inhibitors, such as genistein [37]. This mechanism likely explained the decrease in $H$. pylori colonization in genistein-treated rats in our study, since $H$. pylori adherence to gastric mucosal cells is paramount in the pathogenesis of $H$. pylori infection. Although we do not have prior evidence to suggest that genistein has a bactericidal effect on $H$. pylori, in vitro studies using other bacteria supported that genistein might at least be a bacteriostatic compound [38].

\section{Conclusions}

H. pylori infection is associated with elevated levels of pro-inflammatory mediators (TNF- $\alpha$, and CINC-1), increased neutrophil infiltration in gastric mucosa with H. pylori colonization, and gastric epithelial cell apoptosis. Genistein exerted its gastroprotective effects in rats with $H$. pylori-induced gastropathy through the reduction in NF-kB activation, pro-inflammatory cytokine production, and gastric apoptotic cell death. Clinical studies are needed to confirm the therapeutic effects of genistein in human.

\section{Abbreviations \\ H. pylori: Helicobacter pylori; TNF-a: Tumor necrosis factor-alpha; CINC-1: Cytokine-induced neutrophil chemoattractant-1; NF-kB: Nuclear factor-kap- paB; IL-1: Interleukin-1; IL-6: Interleukin-6; IL-8: Interleukin-8; IL-1 13: Interleukin- 1 beta; EGF: Epidermal growth factor; LPSs: Lipopolysaccharide; TUNEL: \\ Terminal deoxynucleotidyl transferase mediated dUTP nick-end labeling; IHC: Immunohistochemistry; ELISA: Enzyme-linked immunosorbent assay; HE: Hematoxylin-eosin.}

Acknowledgements

The authors would like to thank the Grant of Ratchadaphiseksomphot, Chulalongkorn University, Bangkok, Thailand. 


\begin{abstract}
Authors' contributions
PS designed the study, performed experiments, analyzed data and edited the manuscript; DW designed the study, performed experiments, analyzed data, and wrote the manuscript; NP performed experiments and collected data; KS performed experiments, collected data, and edited the manuscript; TC provided H. pylori for inoculation and edited the manuscript; NK coordinated pathological examinations and edited the manuscript; $\mathrm{MC}$ wrote the manuscript, analyzed data and edited the manuscript. All authors read and approved the final manuscript.
\end{abstract}

\section{Funding}

This study was supported by The Grant of Ratchadaphiseksomphot, Chulalongkorn University, Bangkok, Thailand.

\section{Availability of data and materials}

The datasets used and/or analysed during the current study are available from the corresponding author on reasonable request.

\section{Ethics approval and consent to participate}

All experiments and procedures carried out on the animals have been approved by the Ethics Committee of the Faculty of Medicine, Chulalongkorn University, Bangkok, Thailand (IRB No. 8/57).

\section{Consent for publication}

Not applicable.

\section{Competing interests}

The authors declare that they have no competing interests.

\section{Author details}

${ }^{1}$ Department of Physiology, Faculty of Medicine, Alternative and Complementary Medicine for Gastrointestinal and Liver Diseases Research Unit, Chulalongkorn University, Bangkok 10330, Thailand. ${ }^{2}$ Department of Microbiology, Faculty of Medicine, Alternative and Complementary Medicine for Gastrointestinal and Liver Diseases Research Unit, Chulalongkorn University, Bangkok 10330, Thailand. ${ }^{3}$ Department of Pathology, Faculty of Medicine, Alternative and Complementary Medicine for Gastrointestinal and Liver Diseases Research Unit, Chulalongkorn University, Bangkok 10330, Thailand.

Received: 7 February 2020 Accepted: 23 November 2020

Published online: 09 December 2020

\section{References}

1. Goh K-L, Chan W-K, Shiota S, et al. Epidemiology of Helicobacter pylori infection and public health implications. Helicobacter. 2011;16(Suppl 1(0 1)):1-9.

2. Suzuki H, Masaoka T, Nomura S, et al. Current consensus on the diagnosis and treatment of $\mathrm{H}$. pylori-associated gastroduodenal disease. Keio J Med. 2003;52(3):163-73.

3. Suzuki H, Hibi T, Marshall BJ. Helicobacter pylori: present status and future prospects in Japan. J Gastroenterol. 2007;42(1):1-15.

4. Uemura N, Okamoto S, Yamamoto S, et al. Helicobacter pylori infection and the development of gastric cancer. N Engl J Med. 2001;345(11):784-9.

5. Gerhard M, Rad R, Prinz C, et al. Pathogenesis of helicobacter pylori infection. Helicobacter. 2002;7(Suppl 1):17-23.

6. Selbach M, Moese S, Hurwitz R, et al. The helicobacter pylori CagA protein induces cortactin dephosphorylation and actin rearrangement by C-Src inactivation. EMBO J. 2003;22(3):515-28.

7. Brandt S, KwokT, Hartig R, et al. NF-kappaB activation and potentiation of proinflammatory responses by the helicobacter pylori CagA protein. Proc Natl Acad Sci U S A. 2005;102(26):9300-5.

8. Aihara M, Tsuchimoto D, Takizawa $\mathrm{H}$, et al. Mechanisms involved in helicobacter pylori-induced interleukin- 8 production by a gastric cancer cell line, MKN45. Infect Immun. 1997:65(8):3218-24.

9. Yamaoka Y, Kita M, Kodama T, et al. Helicobacter pylori cagA gene and expression of cytokine messenger RNA in gastric mucosa. Gastroenterology. 1996;110(6):1744-52
10. Zarrilli R, Ricci V, Romano M. Molecular response of gastric epithelial cells to helicobacter pylori-induced cell damage. Cell Microbiol. 1999;1(2):93-9.

11. Cabral MM, Mendes CM, Castro LP, et al. Apoptosis in helicobacter pylori gastritis is related to cagA status. Helicobacter. 2006;11(5):469-76.

12. Handa O, Naito Y, Takagi T, et al. Tumor necrosis factor-alpha-induced cytokine-induced neutrophil chemoattractant-1 (CINC-1) production by rat gastric epithelial cells: role of reactive oxygen species and nuclear factor-kappaB. J Pharmacol Exp Ther. 2004;309(2):670-6.

13. O'Connor A, Liou J-M, Gisbert JP, et al. Review: treatment of helicobacter pylori infection 2019. Helicobacter. 2019;24(S1):e12640.

14. Savoldi A, Carrara E, Graham DY, et al. Prevalence of antibiotic resistance in helicobacter pylori: a systematic review and meta-analysis in World Health Organization Regions. Gastroenterology. 2018;155(5):1372-1382. e1317.

15. Hsu PI, Pan CY, Kao JY, et al. Helicobacter pylori eradication with bismuth quadruple therapy leads to dysbiosis of gut microbiota with an increased relative abundance of Proteobacteria and decreased relative abundances of Bacteroidetes and Actinobacteria. Helicobacter. 2018;23(4):e12498.

16. Akiyama T, Ishida J, Nakagawa S, et al. Genistein, a specific inhibitor of tyrosine-specific protein kinases. J Biol Chem. 1987;262(12):5592-5.

17. Ji G, Zhang Y, Yang Q, et al. Genistein suppresses LPS-induced inflammatory response through inhibiting NF-kappaB following AMP kinase activation in RAW 264.7 macrophages. PLoS One. 2012;7(12):e53101.

18. Hamalainen M, Nieminen R, Vuorela P, et al. Anti-inflammatory effects of flavonoids: genistein, kaempferol, quercetin, and daidzein inhibit STAT-1 and NF-kappaB activations, whereas flavone, isorhamnetin, naringenin, and pelargonidin inhibit only NF-kappaB activation along with their inhibitory effect on iNOS expression and NO production in activated macrophages. Mediat Inflamm. 2007;2007:45673.

19. Choi $\mathrm{C}$, Cho H, Park J, et al. Suppressive effects of genistein on oxidative stress and NFkappaB activation in RAW 264.7 macrophages. Biosci Biotechnol Biochem. 2003;67(9):1916-22.

20. Hong $H$, Landauer MR, Foriska MA, et al. Antibacterial activity of the soy isoflavone genistein. J Basic Microbiol. 2006;46(4):329-35.

21. Ko K-P, Park SK, Park B, et al. Isoflavones from phytoestrogens and gastric cancer risk: a nested case-control study within the Korean Multicenter Cancer Cohort. Cancer Epidemiol Biomark Prev. 2010;19(5):1292-300.

22. Werawatganon D. Simple animal model of helicobacter pylori infection. World J Gastroenterol. 2014;20(21):6420-4

23. Sharma SA, Tummuru MK, Blaser MJ, et al. Activation of IL-8 gene expression by helicobacter pylori is regulated by transcription factor nuclear factor-kappa B in gastric epithelial cells. J Immunol. 1998;160(5):2401-7.

24. Yamaoka Y, Kita M, Kodama T, et al. Chemokines in the gastric mucosa in helicobacter pylori infection. Gut. 1998;42(5):609-17.

25. Maeda S, Yoshida H, Mitsuno Y, et al. Analysis of apoptotic and antiapoptotic signalling pathways induced by helicobacter pylori. Gut. 2002;50(6):771-8.

26. Cover TL, Krishna US, Israel DA, et al. Induction of gastric epithelial cel apoptosis by helicobacter pylori vacuolating cytotoxin. Cancer Res. 2003:63(5):951-7.

27. Moss SF, Calam J, Agarwal B, et al. Induction of gastric epithelial apoptosis by helicobacter pylori. Gut. 1996:38(4):498-501.

28. Tuli HS, Tuorkey MJ, Thakral F, et al. Molecular mechanisms of action of Genistein in cancer: recent advances. Front Pharmacol. 2019:10:1336.

29. Verdrengh $M$, Jonsson IM, Holmdahl R, et al. Genistein as an anti-inflammatory agent. Inflamm Res. 2003;52(8):341-6.

30. Gottstein N, Ewins BA, Eccleston C, et al. Effect of genistein and daidzein on platelet aggregation and monocyte and endothelial function. $\mathrm{Br} J$ Nutr. 2003;89(5):607-16

31. Nozawa Y, Nishihara K, Peek RM, et al. Identification of a signaling cascade for interleukin-8 production by helicobacter pylori in human gastric epithelial cells. Biochem Pharmacol. 2002;64(1):21-30.

32. Segal ED, Lange $C$, Covacci $A$, et al. Induction of host signal transduction pathways by Helicobacter pylori. Proc Natl Acad Sci U S A. 1997:94(14):7595-9.

33. Genta RM, Lew GM, Graham DY. Changes in the gastric mucosa following eradication of helicobacter pylori. Mod Pathol. 1993;6(3):281-9.

34. Takekawa S, Matsui T, Arakawa Y. The protective effect of the soybean polyphenol genistein against stress-induced gastric mucosal lesions 
in rats, and its hormonal mechanisms. J Nutr Sci Vitaminol (Tokyo) 2006;52(4):274-80.

35. Vivatvakin S, Werawatganon D, Somanawat K, et al. Genistein-attenuated gastric injury on indomethacin-induced gastropathy in rats. Pharmacogn Mag. 2017;13(Suppl 2):S306-s310.

36. Hegab II, Abd-Ellatif RN, Sadek MT. The gastroprotective effect of $\mathrm{N}$-acetylcysteine and genistein in indomethacin-induced gastric injury in rats. Can J Physiol Pharmacol. 2018;96(11):1161-70.

37. Su B, Johansson S, Fallman M, et al. Signal transduction-mediated adherence and entry of helicobacter pylori into cultured cells. Gastroenterology. 1999;117(3):595-604
38. Ulanowska K, Tkaczyk A, Konopa G, et al. Differential antibacterial activity of genistein arising from global inhibition of DNA, RNA and protein synthesis in some bacterial strains. Arch Microbiol. 2006;184(5):271-8.

\section{Publisher's Note}

Springer Nature remains neutral with regard to jurisdictional claims in published maps and institutional affiliations.
Ready to submit your research? Choose BMC and benefit from:

- fast, convenient online submission

- thorough peer review by experienced researchers in your field

- rapid publication on acceptance

- support for research data, including large and complex data types

- gold Open Access which fosters wider collaboration and increased citations

- maximum visibility for your research: over $100 \mathrm{M}$ website views per year

At BMC, research is always in progress.

Learn more biomedcentral.com/submissions 